\title{
Regional Cerebral Blood Flow after Hemorrhagic Hypotension in the Preterm, Near-Term, and Newborn Lamb
}

\author{
W. SZYMONOWICZ, A. M. WALKER, V. Y. H. YU, M. L. STEWART, J. CANNATA, AND \\ L. CUSSEN \\ Monash University Department of Paediatrics and Centre for Early Human Development, Monash Medical \\ Centre, Clayton, Victoria, Australia
}

\begin{abstract}
Developmental changes in regional cerebral blood flow (CBF) responses to hemorrhagic hypotension during normoxia and normocapnia were determined using radioactively labeled microspheres to measure flow to the cortex, brainstem, cerebellum, white matter, caudate nucleus, and choroid plexus in three groups of chronically catheterized lambs: 90 - to 100 -d preterm fetal lambs $(n=$ 9); 125- to 136-d near-term fetal lambs $(n=9)$; and newborn lambs 5- to 35-d-old $(n=8)$. Heart rate, central venous pressure, and arterial blood pressure were monitored continuously and arterial blood gas tensions, $\mathrm{pH}, \mathrm{Hb}$, and oxygen saturation together with regional $\mathrm{CBF}$ were measured periodically. Hemorrhagic hypotension produced a mean decrease in arterial blood pressure of $27 \pm 4,23 \pm$ 2 , and $41 \pm 4 \%$ in the three groups, respectively, whereas reinfusion of the lamb's blood resulted in a return to control blood pressure within $3 \%$ in all three groups. In the preterm fetal lamb, CBF decreased significantly in all regions during hypotension. In the near-term fetal lamb, only blood flow to the cortex decreased significantly during hypotension. In the newborn lamb, only the choroid plexus demonstrated a significant decrease in blood flow during hypotension. The lower limit of regional $\mathrm{CBF}$ autoregulation was identical to the resting mean arterial pressure in fetal life but significantly lower in newborn lambs. These experiments demonstrate for the first time that vulnerability to hypotension decreases with increasing maturity and that the brainstem, the phylogenetically oldest region of the brain, is the least vulnerable to the effects of hypotension at any age in the lamb model. (Pediatr Res 28: 361-366, 1990)
\end{abstract}

\section{Abbreviations}

CBF, cerebral blood flow

Autoregulation of CBF has been demonstrated over a wide range of systemic blood pressure in adult animals (1-3) and man (4). However, data regarding autoregulation of regional CBF in newborn animals is sparse $(5-11)$. Data regarding the autoregulation of regional CBF in the newborn lamb (5) and the nearterm lamb (12-14) are very limited and are unavailable in preterm lambs. Moreover, the functional maturity of the autoregulatory mechanism in various cerebral regions has not been

Received June 19, 1989; accepted May 30, 1990.

Correspondence and reprint requests: Adrian M. Walker, Ph.D., Monash University Department of Paediatrics and Centre for Early Human Development, Monash Medical Centre, Locked Bag 29 P.O., Clayton, 3168, Victoria, Australia.

Supported by the National Health and Medical Research Council of Australia. determined in any developmental animal model. Because impairment or absence of cerebrovascular autoregulation in human neonates is thought to be important in the pathophysiology of hemorrhagic and ischemic brain damage $(15,16)$, we chose to investigate the response of regional CBF to hemorrhagic hypotension in animals at preterm, near-term, and newborn ages.

\section{MATERIALS AND METHODS}

Border-Leicester Merino cross ewes with time-dated gestational periods $( \pm 1 / 2$ d) and newborn lambs were used in our studies. Three groups of lambs were chronically catheterized: nine preterm fetal lambs at a mean $93 \mathrm{~d}$ (SD $3 \mathrm{~d}$ ) gestation, nine near-term fetal lambs at $126 \mathrm{~d}$ (SD 4 d) gestation, and eight newborn lambs at $17 \mathrm{~d}$ (SD $10 \mathrm{~d}$ ) after birth. They were studied at a mean of $96 \mathrm{~d}$ gestation, $130 \mathrm{~d}$ gestation, and $20 \mathrm{~d}$ after birth, respectively. The surgical procedures under halothane/oxygen anesthesia and the methods of physiologic measurements have been described in detail (17). Vascular catheters were inserted into the carotid artery, jugular vein, leg vein, and femoral or leg artery in the preterm and near-term fetal lambs and into the carotid artery, jugular vein, axillary artery, and left atrium in the newborn lambs.

Regional CBF was measured by the radionuclide-labeled microsphere method (18). Microspheres, $15 \mu \mathrm{m}$ in diameter labeled with ${ }^{51} \mathrm{Cr},{ }^{85} \mathrm{Sr},{ }^{95} \mathrm{Nb}$, or ${ }^{141} \mathrm{Ce}(3 \mathrm{M}$, St. Paul, MN or New England Nuclear, Boston, MA) were used in random assignment. Approximately $1 \times 10^{6}$ microspheres with a single label were injected into the inferior vena cava in fetal lambs or into the left atrium in newborn lambs over a $30-\mathrm{s}$ period. The reference sample was withdrawn with a pump (Harvard Apparatus Co., Inc., S. Natick, MA) from a carotid arterial catheter beginning $10-15 \mathrm{~s}$ before and ending $90 \mathrm{~s}$ after the microsphere injection at a rate of $2.0 \mathrm{~mL} / \mathrm{min}$ in the preterm fetal lambs and $4.1 \mathrm{~mL} /$ min in the near-term and newborn lambs. The microsphere injections were not associated with changes in heart rate (NT214 cardiotachometer, Neotrace, Sydney, Australia) or blood pressure (pressure transducers, Hewlett-Packard Co., Palo Alto, CA) which were measured continually using a Hewlett-Packard Co. $7758 \mathrm{~A}$ recorder via the leg artery catheter in fetal lambs and the axillary artery catheter in newborn lambs.

Each animal was studied under normoxic, normocapnic conditions at least $72 \mathrm{~h}$ after recovery from surgical implantation of vascular catheters and underwent a period of hemorrhagic hypotension followed by reinfusion of the blood previously removed. Withdrawn blood was stored at $39-40^{\circ} \mathrm{C}$ and later reinfused over 10-30 min. A microsphere injection was done in the control period under baseline conditions, during hypotension, within $5 \mathrm{~min}$ after withdrawal of blood and within $5 \mathrm{~min}$ of reinfusion of the lamb's blood to restore control blood pressure.

At the end of the experiment, the ewe and fetus or newborn 
lamb were killed using $100 \mathrm{mg} / \mathrm{kg}$ pentobarbitone sodium and an autopsy was done to verify catheter placement. The lamb brain was removed, weighed, placed in formalin and, when fully fixed, was dissected into the following regions under the dissecting microscope: right and left cortex separately $(0.8-3.7 \mathrm{~g})$, brainstem $(1.3-3.2 \mathrm{~g})$, cerebellum $(0.5-6.8 \mathrm{~g})$, white matter $(0.03-0.49 \mathrm{~g})$, caudate nucleus $(0.04-0.7 \mathrm{~g})$, and choroid plexus $(0.07-0.3 \mathrm{~g})$. Tissue and reference blood samples were analyzed for radioactivity with a well-type scintillation counter (Searle M1175, Des Plaines, IL). All reference blood samples and cerebral regions contained a minimum of 384 microspheres for each radionuclide used to ensure that errors were limited to within $10 \%$ of the mean distribution at the $95 \%$ confidence level (19).

Regional CBF (mL/100 g/min) was calculated by the following formula:

$$
\mathrm{CBF}=\frac{\mathrm{RBF} \times \mathrm{C} \text { cerebral region }}{\mathrm{C} \text { arterial }}
$$

where $\mathrm{RBF}$ is withdrawal rate of the reference arterial blood sample $(\mathrm{mL} / \mathrm{min}), C$ cerebral region is counts per $100 \mathrm{~g}$ of cerebral tissue, and $\mathrm{C}$ arterial is the total counts in the reference arterial blood sample. Oxygen content was calculated as the product of $\mathrm{Hb}$ oxygen binding capacity $(1.36) \times \mathrm{Hb}$ concentration $\times \mathrm{Hb}$ oxygen saturation.

Statistical analyses included computing the mean, SD, and SEM for each continuously monitored variable, blood gas tensions, $\mathrm{pH}, \mathrm{Hb}$, oxygen saturation, arterial oxygen content, and regional $\mathrm{CBF}$. The percent changes from control values were calculated for blood pressure and regional CBF. The $t$ test for paired data (one-tailed test) was used to determine the significance of reductions in each of these variables from control experimental conditions during hypotension and reinfusion phases.

An autoregulation index for hypotension for each cerebral region was calculated by subtracting the percent change in mean arterial blood pressure from the percent change in regional CBF. $A$ value of 0 for this index indicates a pressure-passive flow change (equal changes in regional $\mathrm{CBF}$ and mean arterial blood pressure). An increasingly positive index reflects increasing autoregulatory capacity (change in regional CBF less than change in mean arterial blood pressure), whereas a negative index indicates that the flow change exceeds the blood pressure change. Thus, decreasing values of the autoregulation index reflect a decreasing capacity to regulate $\mathrm{CBF}$ when blood pressure falls. The significance of the differences in regional CBF autoregulation indices within each age group of animals was tested by analysis of variance and by paired $t$ test using the Bonferroni correction for multiple comparisons.

To determine the lower limit breakpoint of the autoregulatory plateau for each age group, the data from regions in which $\mathrm{CBF}$ decreased significantly during hypotension were normalized to the control value and plotted against mean arterial pressure in the preterm, near-term, and newborn lambs. The breakpoint of each curve was determined mathematically by repetitively forcing best-fit lines through data above and below a test point using the least squares method, using different test points along the curve until the sum of the residuals from the two least square fits was minimal (20).

\section{RESULTS}

Table 1 presents the mean values and SE of the monitored physiologic variables in the preterm, near-term, and newborn lambs during the three experimental phases: control, hypotension, and reinfusion. The control values represent the norm for fetal and newborn lambs at the given ages. Mean arterial pressure decreased significantly during the hypotension phase in all three animal groups $(p<0.0005)$. There were no significant changes in arterial oxygen and carbon dioxide tensions and arterial oxygen saturations in the three phases in all three age groups.
$\mathrm{Hb}$ was significantly lower $(p<0.002, p<0.002$, and $p<0.05$, respectively) during hypotension in all three animal groups due to the acute withdrawal of blood. In the preterm lambs weighing $845 \pm 104 \mathrm{~g}$, a mean blood volume of $27.9 \mathrm{~mL}$ (SD 16.5) was removed. In the near-term lambs weighing $3.349 \pm 0.585 \mathrm{~kg}$, a mean blood volume of $51.9 \mathrm{~mL}$ (SD 35) was removed, and in the newborn lambs weighing $9.325 \pm 3.865 \mathrm{~kg}$, a mean blood volume of $148 \mathrm{~mL}$ (SD 57.9) was removed. These volumes represented 24,11 , and $16 \%$, respectively, of the estimated lamb blood volumes (fetoplacental blood volume $135 \mathrm{~mL} / \mathrm{kg}$; newborn blood volume $100 \mathrm{~mL} / \mathrm{kg})(21,22)$. As a consequence of the fall in $\mathrm{Hb}$, the arterial oxygen content decreased significantly $(p<$ 0.05 ) in the preterm and newborn lambs. However, only in the preterm lamb group was there a significant change in heart rate (+26 bpm, $p<0.05)$. After reinfusion, no significant changes occurred in any parameter in the near-term lamb. During reinfusion phase, the $\mathrm{pH}$ was lower in the preterm and newborn lamb groups $(p<0.05)$, but remained in the normal range. Similarly, the $\mathrm{Hb}$ and arterial oxygen content were lower in the preterm lamb, whereas the $\mathrm{PCO}_{2}$ was higher in the newborn lamb; these values, too, remained in the normal range.

Regional CBF data in each age group during the control period (Table 2) reflect the developmental differences in baseline regional CBF, which we have described in detail (17): higher levels of flow overall in fetal lambs and a reversal of the hierarchy of flow after birth between cortex, brainstem, and cerebellum. Mean arterial blood pressure and regional CBF in the hypotension and reinfusion phases in the preterm, near-term, and newborn lambs are illustrated in Figure $1 a, b$, and $c$, respectively. In the preterm lamb, where a mean decrease in arterial blood pressure of $27 \pm$ $4 \%$ was achieved, no brain region preserved blood flow at control levels; significant $(p<0.05)$ decreases occurred in the brainstem, cerebellum, white matter, caudate nucleus, and choroid plexus. Cortical blood flow decreased in eight of nine animals and averaged $20 \pm 14 \%$ lower for all nine during hypotension, but this did not quite achieve statistical significance overall $(0.1>p$ $>0.05)$. After reinfusion, blood flow recovered to control values in all cerebral regions except in the white matter, where flow remained at the same level as during hypotension $(p<0.05)$.

In the near-term fetal lamb, where a mean decrease in arterial blood pressure of $23 \pm 2 \%$ was achieved, the brainstem, cerebellum, white matter, caudate nucleus, and choroid plexus maintained blood flow at control levels, whereas cortical flow decreased significantly $(p<0.05)$. After reinfusion, the blood flows were not significantly different from control in all cerebral regions.

In the newborn lambs, where a mean decrease in arterial blood pressure of $41 \pm 4 \%$ was achieved, all cerebral regions except the choroid plexus $(p<0.01)$ maintained their blood flow at control levels. After reinfusion, cortical, brainstem, cerebellar, and white matter blood flows tended to increase above control levels, but in all cerebral regions, reinfusion blood flows were not significantly changed from control.

Average values of the autoregulation index for each region in each of the three groups are presented in Figure 2. Significant differences existed between regions in the preterm and newborn lambs $(p<0.05)$, but not in the near-term lamb. In the preterm lamb, the autoregulation index of the brainstem was significantly greater than the white matter and choroid plexus autoregulation indices $(p<0.05)$. In the newborn lamb, the autoregulation index of the brainstem was greater than the cortex, caudate nucleus, and choroid plexus autoregulation indices $(p<0.05)$.

In each group of lambs, the results of breakpoint analyses to define the lower limit of the autoregulatory plateau are illustrated in Figure $3 a-c$. In the preterm lamb, these data are from the brainstem, cerebellum, cortex, white matter, caudate nucleus, and choroid plexus. Here, the lower limit of the autoregulatory plateau was $39 \mathrm{~mm} \mathrm{Hg}$ (Fig. $3 a$ ). In the near-term lamb, similar analysis of the regional CBF data from the cortex showed that the lower limit of the autoregulatory plateau was $45 \mathrm{~mm} \mathrm{Hg}$ 
Table 1. Experimental conditions during control, hypotension, and reinfusion phases*

\begin{tabular}{|c|c|c|c|c|c|c|c|c|c|}
\hline & \multicolumn{3}{|c|}{ Preterm $(n=9)$} & \multicolumn{3}{|c|}{ Near-Term $(n=9)$} & \multicolumn{3}{|c|}{ Newborn $(n=8)$} \\
\hline & Control & Hypotension & Reinfusion & Control & Hypotension & Reinfusion & Control & Hypotension & Reinfusion \\
\hline $\mathrm{pH}$ & $7.346 \pm 0.008$ & $7.333 \pm 0.010$ & $7.321 \pm 0.005 \dagger$ & $7.343 \pm 0.005$ & $7.340 \pm 0.008$ & $7.341 \pm 0.008$ & $7.399 \pm 0.013$ & $7.376 \pm 0.010$ & $7.369 \pm 0.012 \ddagger$ \\
\hline $\mathrm{PCO}_{2}$ (torr) & $43.9 \pm 1.7$ & $44.5 \pm 1.2$ & $45.2 \pm 1.4$ & $47.3 \pm 1.2$ & $47.1 \pm 1.1$ & $47.3 \pm 1.2$ & $39.8 \pm 0.8$ & $40.1 \pm 1.6$ & $41.5 \pm 0.9 \ddagger$ \\
\hline $\mathrm{PO}_{2}$ (torr) & $23.0 \pm 0.8$ & $23.2 \pm 1.1$ & $22.8 \pm$ & & $.3 \pm 0.8$ & $19.4 \pm 0.7$ & $98.3 \pm 2.5$ & $96.2 \pm 2.0$ & $97.3 \pm 1.9$ \\
\hline $\mathrm{Hb}(\mathrm{g} \%)$ & $8.4 \pm 0.1$ & $7.8 \pm 0.2 \dagger$ & $2 \S$ & .3 & $10.2 \pm 0.2 \dagger$ & $10.8 \pm 0.2$ & $9.8 \pm 0.3$ & $9.4 \pm 0.3 \ddagger$ & $9.7 \pm 0.3$ \\
\hline $\mathrm{SaO}_{2}(\%)$ & $65.5 \pm 3.4$ & $60.5 \pm 3.1$ & $62.6=$ & $55.2 \pm 3.3$ & $54.8 \pm 3.6$ & $52.4 \pm 3.3$ & $95.2 \pm 1.1$ & $95.0 \pm 1.0$ & $95.0 \pm 0.9$ \\
\hline $\begin{array}{l}\mathrm{CaO}_{2} \\
\quad\left(\mathrm{vol}^{2} \%\right)\end{array}$ & $7.5 \pm 0.3$ & $6.5 \pm 0.4 \ddagger$ & $6.9 \pm 0.4 \ddagger$ & $8.3 \pm 0.5$ & $7.6 \pm 0.5 \ddagger$ & $7.8 \pm 0.5$ & $12.9 \pm 0.4$ & $12.4 \pm 0.4 \ddagger$ & $12.8 \pm 0.3$ \\
\hline $\begin{array}{l}\text { MABP } \\
\text { (torr) }\end{array}$ & $37.3 \pm 1.3$ & $27.4 \pm 1.9 \|$ & $37.8 \pm 1.5$ & $49.0 \pm 1.6$ & $37.6 \pm 1.6 \|$ & $47.7 \pm 1.2$ & $95.6 \pm 3.5$ & $54.5 \pm 3.2 \|$ & $97.4 \pm 3.1$ \\
\hline $\mathrm{HR}(\mathrm{bpm})$ & $201 \pm 6$ & $227 \pm 11 \ddagger$ & $211 \pm 9$ & $158 \pm 5$ & $150 \pm 10$ & $164 \pm 8$ & $166 \pm 13$ & $168 \pm 13$ & $170 \pm 10$ \\
\hline
\end{tabular}

* Abbreviations: $\mathrm{SaO}_{2}$, arterial oxygen saturation; $\mathrm{CaO}_{2}$ arterial oxygen content; $\mathrm{MABP}$, mean arterial blood pressure; $\mathrm{HR}$, heart rate.

$+p<0.002$.

$\ddagger p<0.05$.

$\S p<0.02$.

$\| p<0.0005$.

Table 2. Regional CBF during control period $(\mathrm{mL} / \mathrm{min} / \mathrm{l} 00 \mathrm{~g}$ )

\begin{tabular}{lccc}
\hline & $\begin{array}{c}\text { Preterm } \\
(n=9)\end{array}$ & $\begin{array}{c}\text { Near-Term } \\
(n=9)\end{array}$ & $\begin{array}{c}\text { Newborn } \\
(n=8)\end{array}$ \\
\hline Brainstem & $129.0 \pm 16.0$ & $214.6 \pm 23.6$ & $68.9 \pm 4.8$ \\
Cortex & $96.0 \pm 12.0$ & $134.8 \pm 13.5$ & $106.5 \pm 13.5$ \\
Cerebellum & $108.4 \pm 14.4$ & $187.6 \pm 17.2$ & $83.1 \pm 9.8$ \\
White matter & $48.9 \pm 8.8^{*}$ & $109.6 \pm 11.3$ & $52.3 \pm 6.7$ \\
Caudate nucleus & $267.4 \pm 119.5$ & $254.2 \pm 88.6$ & $126.4 \pm 13.7$ \\
Choroid plexus & $1298.7 \pm 327.2$ & $1079.3 \pm 135.2$ & $924.7 \pm 156.0$ \\
\hline
\end{tabular}

$$
* n=6 \text {. }
$$

(Fig. 3b). In the newborn lamb, analysis of the regional CBF data from the choroid plexus revealed the lower limit of autoregulation of this region as $85 \mathrm{~mm} \mathrm{Hg}$ (Fig. $3 \mathrm{c}$ ).

\section{DISCUSSION}

No published report has examined the influence of gestational maturity on the regional cerebral autoregulatory capacity. Autoregulation of total $\mathrm{CBF}$ has been documented in the newborn animal (5-11); however, studies examining the development of the autoregulatory mechanism have been limited to near-term experimental animals $(5,12)$ and one report in $118-122 \mathrm{~d}$ gestation fetal lambs (23). The autoregulation of regional CBF has only been examined in newborn piglets (10), newborn dogs $(9,11)$, and near-term fetal lambs $(13,14)$. Our comparison of the preterm, near-term, and newborn lambs has revealed substantial development of CBF autoregulatory capacity from $90 \mathrm{~d}$ gestation represented by an increasing number of cerebral regions exhibiting autoregulation and an increase in the lower limit of the autoregulatory plateau.

The preterm fetal lamb brain has also been used as a model for intracranial hemorrhage (16). A combination of asphyxia with intermittent increases in cerebral intravascular pressure was the most effective method of producing hemorrhages into the germinal layer (16). The preterm fetal lamb brain has an extensive germinal layer overlying the head and body of the caudate nucleus similar to that of a 30 -wk gestation human infant, and the vascular supply to and from the germinal layer is similar to the basic pattern seen in the human preterm infant $(15,16)$. At $125 \mathrm{~d}$, the germinal layer is confined to small patches anterior to the head of the caudate nucleus and the brain resembles that of a term human infant (15). The cortical differentiation and the degree of myelination in the newborn lamb brain resembles that of a 3- to 4-mo-old human infant (15). The internal carotid artery arises from the carotid rete of ungulates and the choroid plexus is proportionately larger in the sheep fetus than in the human infant. Nevertheless, the progressive changes in the lamb

brain enabled us to study developmental changes in regional CBF response to hemorrhagic hypotension.

The autoregulatory capacity of experimental animals has been shown to be abolished with hypoxia at arterial oxygen saturations below $60 \%$ in adult dogs (24) and below $50 \%$ in near-term lambs $(8,13)$, and with hypercapnia at $\mathrm{PCO}_{2}$ levels above 50 torr (24). The experimental conditions in our preterm, near-term, and newborn lambs demonstrated normoxia and normocapnia in all phases. In our studies, the mean arterial oxygen saturations ranged from $52-55 \%$ in the near-term fetal lambs and their autoregulatory abilities appeared intact. These results agree with a previous report in fetal lambs (13), where mean arterial oxygen saturation of $46 \%$ abolished autoregulation. All our lambs maintained $\mathrm{PCO}_{2}$ at or below 50 torr in all phases. Therefore, hemorrhagic hypotension tested the autoregulatory responses in regional CBF during otherwise normal physiologic conditions.

Hemorrhagic hypotension has been used to examine autoregulatory limits previously $(5,10,13,14)$ in piglets and lambs. This procedure causes small statistically significant differences in $\mathrm{Hb}$ concentrations or hematocrit and in arterial oxygen content $(13,14)$ and can alter heart rates, producing either tachycardia or bradycardia dependent upon developmental age $(14,25)$. In our experiments, the preterm, near-term, and newborn lambs demonstrated a similar small but significant hemodilution during hypotension. Only in the preterm lamb did the animals develop a small but significant tachycardia (mean increase of $13 \%$ ). With fetal hypotension due to acute hemorrhage, vascular volume has been shown to be rapidly restored by shifts of interstitial and transplacental fluid to the vascular compartment with only mild hemodilution (26). In our experiments, the mean decreases in $\mathrm{Hb}$ were 4,6 , and $7 \%$ in the preterm, near-term, and newborn lambs, respectively. For arterial oxygen content, the mean decreases were 4,8 , and $13 \%$, respectively. These changes alone are not of sufficient magnitude to significantly alter $\mathrm{CBF}$ in lambs (27).

In the preterm fetal lamb under ideal physiologic conditions of this study, the resting mean arterial blood pressure was 37 and the lower limit of autoregulatory plateau was $39 \mathrm{~mm} \mathrm{Hg}$ (Fig. $3 a$ ). The lower limit of autoregulation for total CBF was found to be $45 \mathrm{~mm} \mathrm{Hg}$ in preterm lambs of 118-122 d gestation, close to the resting mean arterial pressure of $54 \mathrm{~mm} \mathrm{Hg} \mathrm{(23).} \mathrm{The}$ greater immaturity of our preterm lambs of $90-100 \mathrm{~d}$ gestation probably explains the lower autoregulatory limit, inasmuch as it increases with age together with mean arterial pressure. In preterm lambs, there was a substantial dependence of regional CBF on mean arterial pressure. Only in the brainstem was autoregulation evident; $\mathrm{CBF}$ in this region declined $8 \%$ when mean arterial blood pressure was decreased $27 \%$. In the cortex, eight of nine animals demonstrated reduced blood flow, with the 


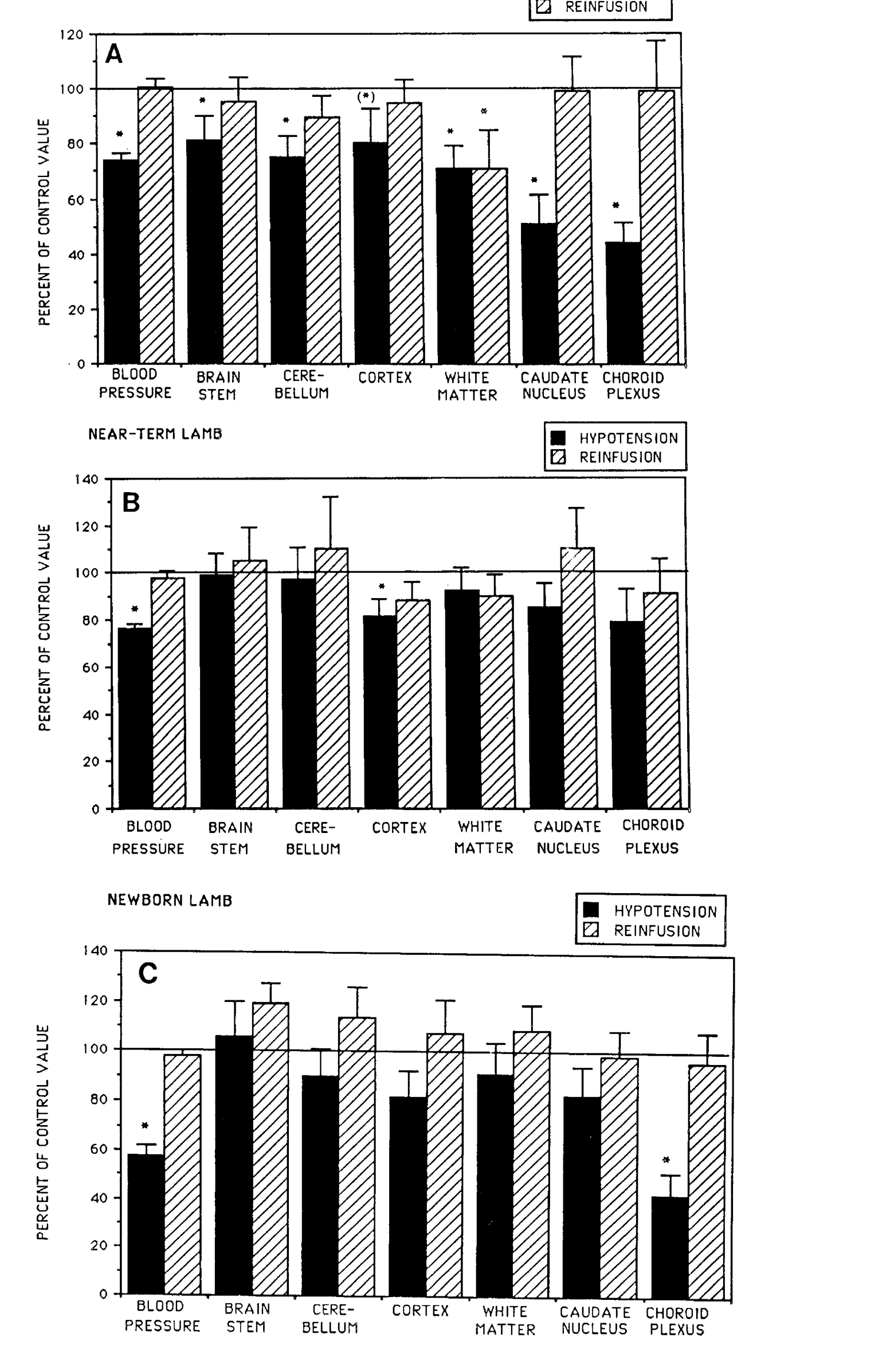




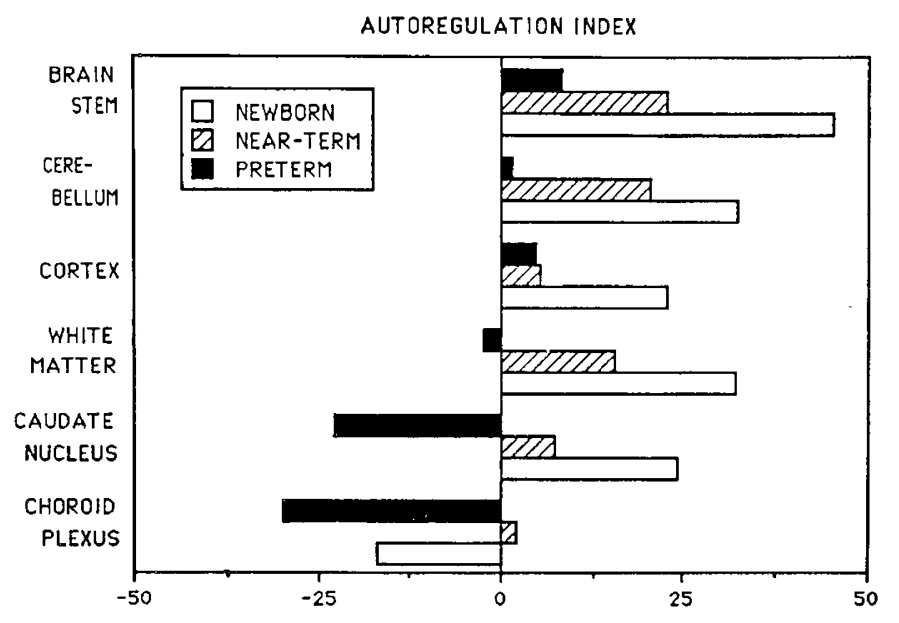

Fig. 2. Values of regional $\mathrm{CBF}$ autoregulation index (percent change of CBF minus percent change of mean arterial blood pressure) for preterm, near-term, and newborn lambs.

exception of one animal in which the flow increased markedly. As a result, the mean decrease in flow failed to achieve statistical significance. As the autoregulation index was virtually zero in the cerebellum, cortex, and white matter, blood flow in these regions was essentially pressure passive. The markedly negative autoregulation index in the caudate nucleus and choroid plexus emphasizes that these regions are extremely vulnerable to hypotension, inasmuch as their flow decreases exceed the decreases in mean arterial blood pressure. In contrast, the positive autoregulation index in the brainstem illustrates that this is the only region capable of any autoregulation in the face of hemorrhagic hypotension in the preterm lamb (Fig. 2).

In the near-term fetal lamb under physiologic conditions, the resting mean arterial blood pressure is $49 \mathrm{~mm} \mathrm{Hg}$. When blood pressure was decreased $23 \%$, regional CBF was maintained in the brainstem, cerebellum, white matter, caudate nucleus, and choroid plexus. Thus, we found an intact autoregulatory capacity in all regions except the cortex. The lower threshold of the autoregulatory plateau for the cortex is $45 \mathrm{~mm} \mathrm{Hg}$. Our data are consistent with previously published reports that autoregulation is maintained down to 43,41 , and $42 \mathrm{~mm} \mathrm{Hg}$ for total CBF (5, $12,13)$ and $42 \mathrm{~mm} \mathrm{Hg}$ for regional CBF (13) in the cerebral hemispheres, basal ganglia, cerebellum, and brainstem in nearterm fetal lambs. Significantly decreased blood flow to the cortex during hypotension is a finding previously unreported in nearterm fetal lambs. However, other studies that indicated that CBF is maintained during hypotension of this magnitude $(5,12,13)$ did not specifically examine the cortex. In contrast, the positive autoregulation index indicated that the autoregulatory capacity of the brainstem, cerebellum, white matter, and caudate nucleus was intact.

In the newborn lamb under the normoxemic, normocapnic conditions of our study, the resting mean arterial blood pressure was $96 \mathrm{~mm} \mathrm{Hg}$, and all but one cerebral region autoregulated well in the face of marked hypotension. Thus, for these regions, the lower limit of the autoregulatory plateau was less than 46 $\mathrm{mm} \mathrm{Hg}$, the lowest pressure examined. This finding agrees with the original value of $40 \mathrm{~mm} \mathrm{Hg}$ in newborn lambs (5). A mean decrease in blood pressure of $41 \%$ resulted in significantly reduced blood flow only to the choroid plexus, and was reflected in the negative autoregulation index. In this region, the lower limit of the autoregulatory curve was $85 \mathrm{~mm} \mathrm{Hg}$. Thus, in the newborn lamb, the choroid plexus remains extremely vulnerable to hypotension.

\section{PRETERM LAMB}

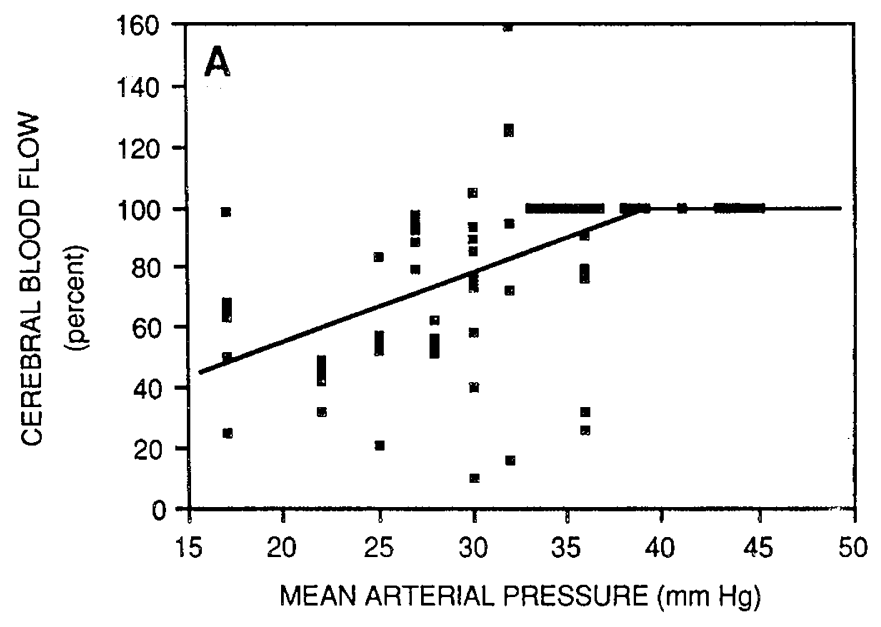

NEAR-TERM LAMB

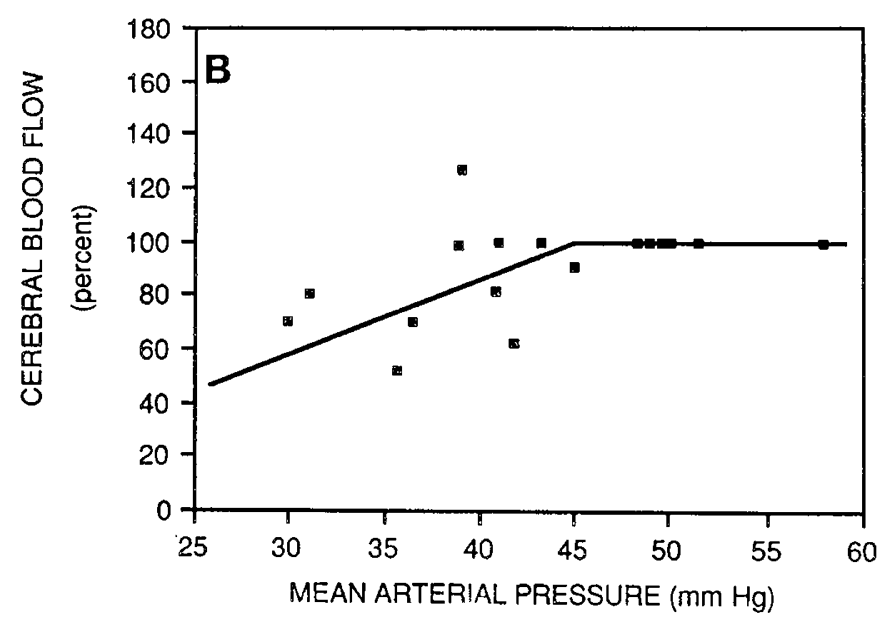

NEWBORN LAMB

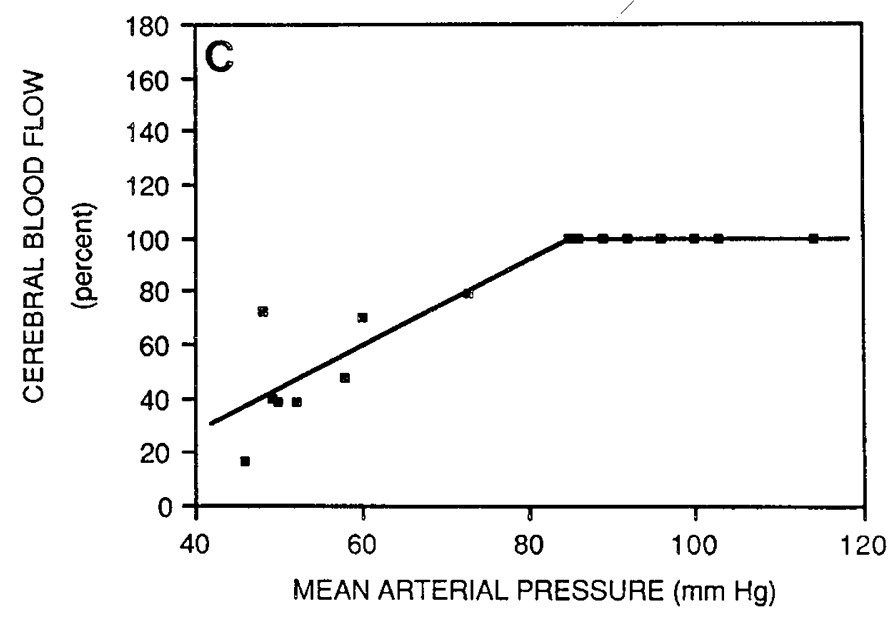

Fig. 3. CBF data from regions with significantly decreased flow during hypotension (percent of control value) vs mean arterial blood pressure for $(a)$ preterm, $(b)$ near-term, and $(c)$ newborn lambs. Lower limits of the autoregulatory plateau (defined by least squares analysis) are 39, 45, and $85 \mathrm{~mm} \mathrm{Hg}$, respectively, for these age groups.

Fig. 1. Mean arterial blood pressure and regional $\mathrm{CBF}$ (percent of control values, mean $\pm \mathrm{SE}$ ) after hemorrhagic hypotension and reinfusion in (a) preterm, $(b)$, near-term, and $(c)$ newborn lambs. ${ }^{*} p<0.05 ;\left(^{*}\right) 0.10>p>0.05$. 
Our data reveal important developmental differences in regional cerebral autoregulation in the lamb model associated with the increasing resting arterial blood pressure in preterm, nearterm, and newborn lambs (37, 49, and $96 \mathrm{~mm} \mathrm{Hg}$, respectively). First, in the preterm lamb, no cerebral region maintained flow and, in fact, the resting mean arterial blood pressure was identical to the breakpoint of the autoregulatory curve for these regions. In the near-term lamb, more regions demonstrated an autoregulatory capacity, but the autoregulatory breakpoint of the region unable to maintain control CBF was again indistinguishable from the resting mean arterial blood pressure. By contrast, in the newborn, all regions with the exception of the choroid plexus demonstrated autoregulatory capacity. In the choroid plexus, the autoregulatory breakpoint was $11 \mathrm{~mm} \mathrm{Hg}$ below the resting mean arterial blood pressure. Recently, a relationship of this form based upon a comparison of studies, each examining a single developmental stage, has been suggested (23).

Second, our data demonstrate for the first time that with increasing maturity there is increasing autoregulatory capacity of regional CBF. The preterm fetal lamb has little ability to autoregulate blood flow in the face of hemorrhagic hypotension except in the brainstem. This finding is in contrast to the autoregulatory abilities of the near-term fetal lamb exposed to the same hypotensive insult and in marked contrast to the autoregulatory abilities of the newborn lamb exposed to much greater hypotensive insults. Lower resting $\mathrm{PCO}_{2}$ of the newborn lamb (40 torr compared with 45 torr in fetal lambs) should enhance the autoregulatory capacity after birth, inasmuch as the comparative cerebral vasoconstriction would provide a greater vasodilatory reserve in the face of hypotension. However, more data, particularly from studies of the preterm lamb, are needed to address the physiologic basis of these developmental differences.

Third, our data confirm that, as in the piglet (7), during hypotension the phyogenetically oldest region of the brain autoregulates better than the other cerebral regions in the pre-term, near-term, and newborn lambs. In contrast, the choroid plexus is the only region unable to autoregulate during hypotension in both fetal and newborn lambs. Even in adult sheep, choroid plexus blood flow remains extremely vulnerable to hypotension (28).

Finally, the regions vulnerable to hypotension differ at each developmental stage. The regions most vulnerable to reductions in flow during hypotension are the white matter, caudate nucleus, and choroid plexus in the preterm lamb. In the near-term lamb, the cortex is vulnerable to hypotension. In contrast, only the choroid plexus remains similarly vulnerable in newborn lambs. In summary, our study indicates that, even under normal physiologic conditions in utero, the preterm brain is especially vulnerable to hypotension.

Additional study is needed to determine whether autoregulation is further impaired by asphyxia in the preterm lamb (13). Vulnerability to hypotension and lack of autoregulatory capacity in the white matter, caudate nucleus, and choroid plexus of the preterm lamb brain, which has been successfully used as an experimental model for intraventricular hemorrhage (16), may well be the critical elements in the pathogenesis of both perinatal hemorrhagic and ischemic damage (15) in the preterm neonate's brain, whereas the continuing vulnerability of the cortex and choroid plexus in the older lamb brain may explain the occurrence of ischemic and hemorrhagic injury at these sites in the term neonate's brain (15).

\section{REFERENCES}

1. Harper AM 1966 Autoregulation of cerebral blood flow: influence of the arterial blood pressure on the blood flow through the cerebral cortex. $J$ Neurol Neurosurg Psychiatry 29:398-403

2. Fitch W, Ferguson GG, Sengupta D, Caribi J, Harper AM 1976 Autoregulation of cerebral blood flow during controlled hypotension in baboons. J Neurol Neurosurg Psychiatry 39:1014-1022

3. Heistad DD, Marcus ML, Piegors DJ, Armstrong ML 1980 Regulation of cerebral blood flow in atherosclerotic monkeys. Am J Physiol 239:45394544

4. Kety SS, King BD, Horvath SM, Jeffers WA, Hafkenschiel JH 1950 The effect of an acute reduction in blood pressure by means of differential spinal sympathetic block on the cerebral circulation of hypertensive patients. J Clin Invest 29:402-407

5. Purves MJ, James IM 1969 Observations on the control of cerebral blood flow in the sheep fetus and newborn lamb. Circ Res 25:651-667

6. Hernandez MJ, Brennan RW, Bowman GS 1980 Autoregulation of cerebral blood flow in the newborn dog. Brain Res 184:199-202

7. Laptook A, Stonestreet BS, Oh W 1982 Autoregulation of brain blood flow in the newborn piglet: regional differences in flow reduction during hypotension. Early Hum Dev 6:99-107

8. Tweed A, Cote J, Low H, Gregory G, Wade J 1986 Impairment of cerebral blood flow autoregulation in the newborn lamb by hypoxia. Pediatr Res 20:516-519

9. Pasternak JF, Groothuis DR 1985 Autoregulation of cerebral blood flow in the newborn beagle puppy. Biol Neonate 48:100-109

10. Laptook AR, Stonestreet BS, Oh W 1983 Brain blood flow and $\mathrm{O}_{2}$ delivery during hemorrhagic hypotension in the piglet. Pediatr Res 17:77-80

11. McPhee AJ, Kotagal UR, Kleinman LI 1985 Cerebrovascular hemodynamics during and after recovery from acute asphyxia in the newborn dog. Pediatr Res 19:645-650

12. Tweed WA, Cote J, Wade JG, Gregory G, Mills A 1982 Preservation of fetal brain blood flow relative to other organs during hypovolemic hypotension. Pediatr Res 16:137-140

13. Tweed WA, Cote J, Pash M, Lou H 1983 Arterial oxygenation determines autoregulation of cerebral blood flow in the fetal lamb. Pediatr Res 17:246249

14. Ashwal S, Dale PS, Longo LD 1984 Regional cerebral blood flow: studies in the fetal lamb during hypoxia, hypercapnia, acidosis and hypotension. Pediatr Res 18:1309-1316

15. Pape KE, Wigglesworth JS 1979 The clinico-pathological relationships and aetiological aspects of intraventricular haemorrhage. Haemorrhage, ischaemia and the perinatal brain. In: Clinics in Developmental Medicine Nos. 69/70. Spastics International Medical Publications of Lippincott, Suffolk, pp 133-148

16. Reynolds ML, Evans CAN, Reynolds EOR, Saunders NR, Durbin GM Wigglesworth JS 1979 Intracranial haemorrhage in the preterm sheep fetus. Early Hum Dev 3:163-186

17. Szymonowicz W, Walker AM, Cussen L, Cannata J, Yu VYH 1988 Developmental changes in regional cerebral blood flow in fetal and newborn lambs. Am J Physiol 254:H52-H58

18. Heymann MA, Payne BD, Hoffmann JI, Rudolph AM 1977 Blood flow measurements with radionuclide-labelled particles. Prog Cardiovasc Dis 20:55-79

19. Buckberg GD, Luck JC, Payne B, Hoffmann JIE, Archie J, Fixler DE 197 Some sources of error in measuring regional blood flow with radioactive microspheres. J Appl Physiol 31:598-604

20. Orr GW, Green HJ, Hughson RL, Bennett GW 1982 A complete linear regression model to determine ventilatory anaerobic threshold. J Appl Physiol 52:1347-1352

21. Creasy RK, Drost M, Green MV, Morris JA 1970 Determination of fetal, placental and neonatal blood volumes in the sheep. Circ Res 27:487-494

22. Creasy RK, Drost M, Green MV, Morris JA 1972 Effect of ventilation on transfer of blood from placenta to neonate. Am J Physiol 222:186-188

23. Papile LA, Rudolph AM, Heymann MA 1985 Autoregulation of cerebral blood flow in the preterm fetal lamb. Pediatr Res 19:159-161

24. Haggendal E, Johansson B 1965 Effects of arterial carbon dioxide tension and oxygen saturation on cerebral blood flow autoregulation in dogs. Acta Physiol Scand 66 (Suppl 258):27-53

25. Walker AM Cannata JP, Ritchie BC, Maloney JE 1983 Hypotension in fetal and newborn lambs: different patterns of reflex heart rate control revealed by autonomic blockade. Biol Neonate 44:358-365

26. Brace RA 1983 Fetal blood volume response to acute fetal hemorrhage. Circ Res 52:730-734

27. Peeters LL, Sheldon RE, Jones Jr MD, Makowski EL, Meschia G 1979 Blood flow to fetal organs as a function of arterial oxygen content. Am J Obstet Gynecol 135:637-646

28. Page RB, Funsch DJ, Brennan RW, Hernandez MJ 1980 Choroid plexus blood flow in the sheep. Brain Res 197:532-537 